\title{
Fabricação, Montagem e Desmontagem de Instalações Provisórias para Canteiros de Obras
}

Fernando Braga de Souza Sheyla Mara Baptista Serra

\section{Introdução}

Entre os vários ambientes previstos para o canteiro de obras estão as áreas de vivência (refeitórios, sanitários, vestiários, alojamentos, etc.) e as áreas administrativas (escritórios, salas de reunião, almoxarifados, etc.), que devem ser dimensionadas e projetadas para o uso correto. De acordo com Dias (2013), a distribuição das áreas de vivência e o posicionamento das instalações temporárias necessárias em uma obra são tradicionalmente feitos de maneira empírica, prevalecendo, muitas vezes, as experiências dos empreendimentos anteriores, sendo comumente executadas sem qualidade e por mão de obra não qualificada.

Em contrapartida, a Norma Regulamentadora NR-18 - Condições e meio ambiente do trabalho na indústria da construção (BRASIL, 2015) solicita, desde sua reedição em 1995, que seja feita a elaboração do projeto do canteiro de obras e, mais recentemente, a "previsão de dimensionamento das áreas de vivência". Considerando a necessidade de incorporar benefícios sociais, econômicos e ambientais ao empreendimento durante a fase de execução, o planejamento do projeto ou layout do canteiro e a definição do sistema construtivo das instalações provisórias estão se tornando aspectos relevantes para melhorar a gestão das obras. 
Essas instalações são consideradas temporárias ou provisórias, ou seja, somente estarão presentes na obra durante a fase de execução e enquanto houver disponibilidade do local no canteiro. Depois são desconstruídas ou desmontadas e, eventualmente, remontadas. Neste caso, é interessante considerar que o processo de desmontagem tenha sido planejado e que a concepção do sistema construtivo preveja o reaproveitamento e remontagem (SOUZA, 2016). A pré-fabricação surge, então, como uma alternativa racionalizada e produtiva para uso em instalações provisórias (IP) do canteiro, facilitando as fases de montagem e de desmontagem, desde o processo de concepção do projeto.

Para Saurin e Formoso (2006), a combinação de espaço limitado com o amplo número de elementos que compõem um canteiro de obra torna a concepção do projeto do ambiente similar à montagem de um "quebra-cabeça", necessitando de criatividade por parte do projetista para encontrar soluções viáveis e adequadas à realidade do canteiro.

Neste sentido, a metodologia Building Information Modeling (BIM), que tem sido utilizada para a elaboração de projetos na construção civil (SACKS; PARTOUCHE, 2010), pode ser empregada para o desenvolvimento do projeto do canteiro de obras e de suas respectivas instalações provisórias.

Os aplicativos BIM possuem, em geral, bibliotecas com componentes típicos da indústria da arquitetura, engenharia e construção (AEC). Essas bibliotecas podem ser também acrescidas dos produtos e catálogos disponibilizados pelos fabricantes da construção provisória pré-fabricada. Deste modo, o projeto é feito por meio da composição de elementos de construção, o que o torna muito similar à lógica da construção pré-fabricada.

As oportunidades de uso dos modelos BIM no canteiro de obras para IP préfabricadas podem ser úteis para comparar o caso real ao modelo virtual 4D (que considera as três dimensões espaciais e o tempo), tanto no processo de montagem quanto no de desmontagem, visando otimizar esses processos.

A necessidade de projetos sustentáveis - adequados do ponto de vista econômico, social e ambiental - e a necessidade e possibilidade de reutilização das construções temporárias para uso em canteiro de obras justifica o uso de aplicativos para a concepção, projeto, montagem e desmontagem do processo de fabricação e execução das instalações provisórias em canteiro de obras. 


\section{Método de Pesquisa}

O trabalho desenvolveu-se tendo por base a pesquisa de Souza (2016) apoiada pela rede CANTECHIS/FINEP. A investigação utilizou-se dos métodos de estudo de caso e de simulação, divididos em três etapas:

- Primeiramente, fez-se a revisão bibliográfica para estabelecer a base teórica necessária para o desenvolvimento da pesquisa.

- Em seguida, foram realizados os estudos de caso. Elaborou-se um roteiro para a coleta de dados acerca dos processos de projeto, fabricação, montagem, desmontagem e reutilização das IP pré-fabricadas. Foram desenvolvidos roteiros de investigação para os dois ambientes: a fábrica das IP e o canteiro de obras. A coleta de dados foi efetuada por meio de visitas e entrevistas.

- Por fim, foram propostas as simulações virtuais de fabricação, montagem e desmontagem das IP pré-fabricadas em madeira a partir dos levantamentos realizados, com o objetivo de definir antecipadamente o processo de produção, propondo melhorias e facilitando o treinamento dos operários envolvidos. Pretendeu-se também demonstrar a viabilidade de projetos voltados para os processos de montagem e desmontagem das IP.

Os programas utilizados foram:

- AutoCAD com recursos para projeto em CAD 2D, assim como recursos de CAD 3D integrados, permitindo modelagem 3D, desenho 3D e elaboração de maquete eletrônica.

- SketchUp é um software voltado para a modelagem e desenho 3D. O SketchUp Pro permite o uso de ferramentas de programação, diagramação, volumetria, desenvolvimento e detalhamento de desenhos, bem como gerar respostas a solicitações de informação.

- O MS Project é um programa gerenciador de projetos, que auxilia na construção do cronograma das atividades e que facilita a discussão entre os agentes da construção.

- O software Navisworks da Autodesk possibilita a revisão do projeto e simulação da construção, permitindo que se incorporem modelos 3D em uma disposição temporal.

A Figura 1 apresenta a sequência de etapas desenvolvidas durante a pesquisa. 


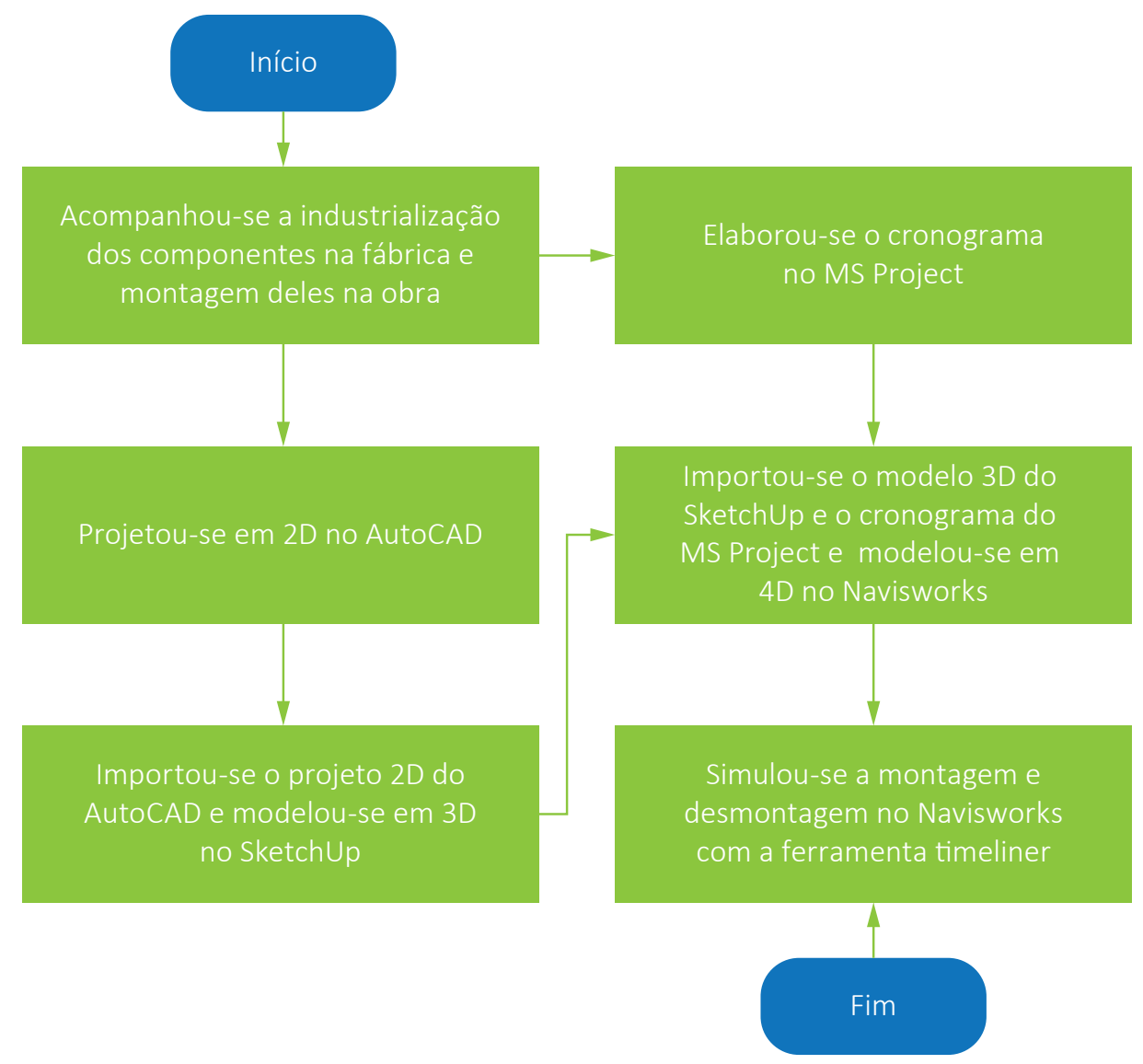

Figura 1 - Etapas para a simulação dos processos estudados. Fonte: Souza, 2016.

\section{Concepção de Sistemas Construtivos Pré-fabricados}

O termo pré-fabricação, no campo da construção civil, possui o seguinte significado: "fabricação de certo elemento antes do seu posicionamento final na obra", segundo Revel (1973). Para esse autor, a pré-fabricação em seu sentido mais geral pode ser aplicada à fabricação de componentes e sistemas construtivos, que são produzidos em indústrias e, posteriormente, transportados à obra para montagem da edificação.

A decomposição da unidade habitacional em partes ou elementos préfabricados faz com que a construção seja cada vez mais um processo de montagem do que de construção propriamente dito. A fabricação dos elementos é normalmente feita em indústrias cujo controle de qualidade da produção é maior e cuja exposição a 
intempéries é reduzida. Os elementos são normalmente padronizados e catalogados para o perfeito encaixe no sistema idealizado.

O projeto realizado com componentes pré-fabricados implica no conhecimento do projetista do processo de fabricação dos elementos, do transporte, da montagem e das ligações necessárias. Por esse motivo, é importante que todas essas etapas sejam determinadas logo na concepção do projeto. O projetista do sistema deve atuar como agente de integração entre as disciplinas, facilitando a padronização das soluções e compatibilidade entre os sistemas prediais adotados.

No caso dos projetos das IP pré-fabricadas, eles são concebidos, normalmente, pelo setor de projetos da empresa fabricante desse tipo de estrutura. Dias (2013) visitou três empresas fabricantes que, além de possuírem setor próprio de projetos, possuíam soluções padronizadas para as principais demandas do mercado, como almoxarifados, refeitórios, sanitários e vestiários. Várias empresas encontradas atualmente no mercado brasileiro, inclusive, disponibilizam as soluções padronizadas em seus sites comerciais.

A construção com componentes pré-fabricados, mesmo sendo provisória, pressupõe que o projetista e fabricante utilizem conceitos como construtibilidade, modularidade, desempenho e segurança. O diferencial desse tipo de construção é que o projeto deve comtemplar, necessariamente, o processo de desconstrução e remontagem.

Assim, de forma a desenvolver um conhecimento que contribua para o processo de desconstrução, Crowther (2002) propõe alguns princípios com foco na construtibilidade dos projetos com sistemas pré-fabricados, a saber:

- Redução do número de diferentes tipos de componentes: visa simplificar o processo de seleção no canteiro e aumentar o valor do componente;

- Uso de sistemas abertos em que as partes da construção são mais livremente intercambiáveis: permite alterações do layout por meio da relocação de componentes sem uma significativa modificação;

- Uso de modulação: componentes e elementos que são compatíveis com outros sistemas em termos dimensionais e funcionais;

- Uso de tecnologias montáveis compatíveis: não exige especialistas para a desmontagem;

- Uso de componentes com tamanho adequado aos meios de montagem: facilitar o manuseio em todas as fases (montagem, desmontagem, transporte, reprocessamento e remontagem);

- Provimento dos meios de manuseio dos componentes durante a montagem e desmontagem: prever pontos de conexão que podem ser necessários para içar ou suportar temporariamente os componentes; 
- Estudo de ligações e conexões para o reuso dos componentes: minimizar as quebras ou deformações dos componentes e materiais durante os processos de montagem, desmontagem e remontagem;

- Permissão da desmontagem paralela em vez da sequencial: um componente pode ser removido sem a quebra de outro componente; quando isso não for possível, o componente mais passível de reuso deve ter prioridade;

- Uso de sistemas pré-fabricados: reduzir o trabalho em canteiro e permitir um maior controle da qualidade e da conformidade dos componentes;

- Fornecimento de peças de reposição no canteiro: principalmente dos componentes quebrados ou danificados para não alterar o projeto da edificação;

- Manutenção das condições dos componentes: garantir a preservação dos componentes, como as dimensões do produto, tempo de vida útil e necessidades de manutenção.

Por meio das características citadas anteriormente, verifica-se o potencial de utilização do conceito de desconstrução visando às instalações provisórias em canteiro.

\section{Desconstrução}

Para Couto et al. (2006), a demolição seletiva ou desconstrução surgiu em virtude do rápido crescimento da demolição de edifícios e da evolução das preocupações ambientais da população. Segundo esses autores, a desconstrução de um edifício é um processo que se caracteriza pelo seu desmantelamento ou desmontagem cuidadosa, de modo a reduzir os resíduos e possibilitar a recuperação, reaproveitamento ou reuso dos materiais e componentes da construção.

Enquanto a demolição tradicional visa remover a edificação o mais rápido possível, a desconstrução ou demolição seletiva busca separar os materiais para o reuso e reciclagem (LIPSMEIER e GÜNTHER, 2002).

O procedimento de desconstrução deve ser planejado e documentado para que os envolvidos possam desenvolvê-lo de forma coordenada, eficiente, eficaz e segura (ITEC, 1995). A forma mais segura de realizar uma desconstrução é fazendo a desmontagem em sequência inversa ao processo de construção, retirando-se louças, cobertura, esquadrias etc., como pode ser visto no esquema da Figura 2. 

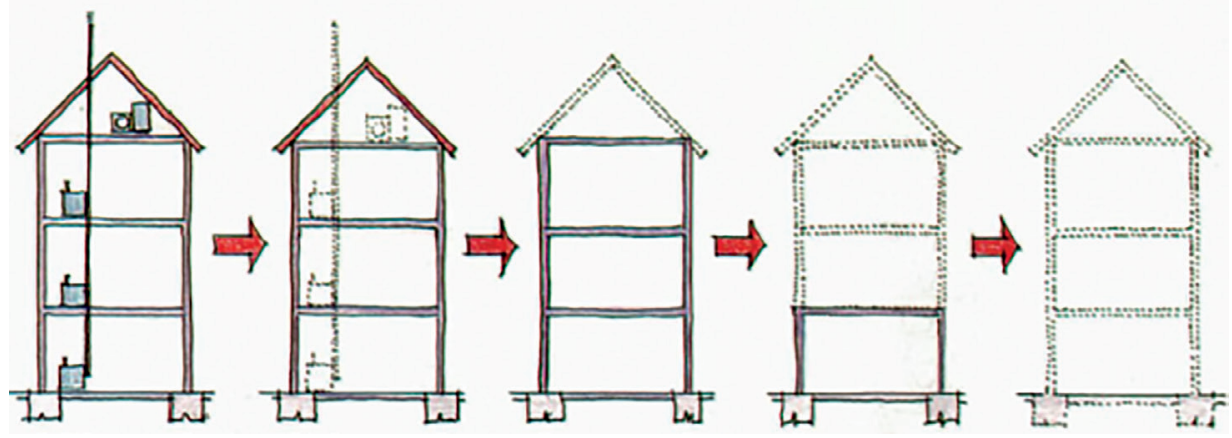

Figura 2 - Sequência de desconstrução de uma edificação. Fonte: ITEC, 1995.

O projeto para a desmontagem pode aumentar, inicialmente, o custo de produção. Contudo, a desconstrução em larga escala tem um grande potencial de trazer benefícios à sociedade (CROWTHER, 2002). Alguns dos benefícios da desconstrução em relação à demolição são segundo Kibert e Chini (2000):

- Diminuição do direcionamento de resíduo para aterros;

- Potencial reuso dos componentes construtivos;

- Maior facilidade de reciclagem dos materiais;

- Menor impacto ambiental.

De acordo com Kibert e Chini (2000), o processo de desconstrução preserva a energia incorporada investida na produção dos elementos, reduzindo o consumo de uma nova energia no processamento ou manufatura. A energia incorporada pode ser entendida como a energia requerida para produzir um produto, que inclui os processos de obtenção da matéria-prima, transporte, manufatura e de produção das máquinas e infraestrutura usada nessas atividades (MANFREDINI; SATTLER, 2005).

Segundo Lopes (2013), o projeto da desconstrução deve determinar a forma de reutilização, de transporte e de armazenamento dos materiais para reuso, e terminar o custo desse planejamento. Para essa autora, pode haver aumento dos custos e adição, em vez de redução, da energia incorporada ao projeto. Uma das recomendações é utilizar os materiais recuperados em locais próximos.

Para a desconstrução, são utilizados métodos não destrutivos. Os equipamentos recomendados para este processo são os que possibilitam a desmontagem dos componentes e o seu manuseio de forma segura e rápida, garantindo a integridade desses elementos.

Verifica-se potencial de aplicação da desconstrução para as instalações provisórias nos canteiros de obras. Como mencionado, o projeto deve prever esta situação, por isso, ele deve ser estudado com cuidado. A seguir serão citados métodos 
para o desenvolvimento do projeto de produtos que sistematizam o processo de montagem e desmontagem, podendo ser aplicado também na construção civil.

\subsection{Design For Assembly}

Design For Assembly (DFA), em português, Projeto para Montagem, é um método de análise que fornece uma estrutura de orientações para que o produto seja desenvolvido de forma a facilitar o processo de montagem, segundo Amaral (2007). Esse autor menciona que as bases do método são a redução das partes por meio da diminuição do número de peças por produto e da variedade de tipos de peças e mediante a utilização do conceito de coordenação modular. Com isso, busca-se a confecção de módulos, que podem ser montados, desmontados e trocados com mais facilidade.

De acordo com Kuo et al. (2001), a aplicação do DFA em projetos proporciona a simplificação de produtos, a redução do ciclo de produção, minimiza os custos de fabricação e montagem e possibilita que a fase de produção seja estudada de forma antecipada, evitando erros de projeto. Para vários autores, o objetivo principal do DFA é a redução do ciclo de produção e do custo envolvido. A concepção do processo de montagem, ainda, reflete um necessário planejamento no que diz respeito à conservação ambiental, uma vez que os projetos consideram a sustentabilidade dos produtos gerados.

Vivan e Paliari (2012) aplicaram o DFA a uma edificação em sistema construtivo pré-fabricado em Light Steel Frame e apresentaram várias diretrizes para o processo de projeto e sua consequente representação. Como recomendação, os autores mencionaram que a aplicação do DFA pode ser altamente facilitada pelo uso de tecnologia da informação a partir de softwares BIM.

No caso das IP, entende-se que o processo de produção dos componentes em fábrica pode se beneficiar também dos conceitos do DFA.

\subsection{Design For Disassembly}

O Design For Disassembly (DFD), em português, Projeto para Desmontagem, é o processo de concepção de produtos, de modo que eles possam ser rápida e facilmente desmontados no final de sua vida útil, de forma rentável, e que proporcione a reutilização e/ou reciclagem dos componentes (BOOTHROYD; ALTING, 1992).

A concepção do DFD, por sua vez, considera que todo o processo posterior de desmontagem é pensado durante o desenvolvimento do projeto inicial, o que acarreta grandes benefícios para o reaproveitamento dos materiais e, logo, em um maior cuidado com o impacto ambiental. O processo de reuso, reciclagem e potencial conserto dos materiais gerados têm sido designados por diferentes nomes. 
O DFD aplicado à construção de edifícios, segundo Guy (2003), precisa considerar a criação de um plano de desconstrução que considere a rotulagem dos materiais e dos componentes constitutivos, categorizando-os de forma antecipada. Durante o processo de desmantelamento, é importante priorizar a disposição dos materiais na ordem de reutilização, remanufatura, reciclagem ou eliminação. O plano de desconstrução também deve prever o planejamento da gestão, programação e requisitos de segurança do processo de desconstrução.

Neste sentido, Barkkume (2008) argumenta que a desconstrução de edifícios não ocorre da maneira simplificada, sendo uma atividade complexa, que requer grande contingente de pessoas para sua realização, com necessárias considerações de segurança e saúde. Por isso, deve ser antecipadamente preparada durante a fase de projeto do produto, considerando os princípios do DFD. Para o referido autor, a desconstrução é uma alternativa inteligente à demolição, com fins de salvar materiais, componentes e a energia incorporada total.

Segundo Guy (2003), a tendência em pré-comercializar materiais para reutilização e reciclagem fornece um incentivo econômico para a desconstrução. Assim, Guy e Ohlsen (2003) desenvolveram um software para facilitar a análise do "negócio" da desconstrução, permitindo que os empreiteiros estimem o custo e o potencial de receita. Usando o computador, a ferramenta apresenta dados sobre a viabilidade da desconstrução e identifica variáveis econômicas, como uso de mão de obra local e custos de materiais recicláveis. O programa foi inicialmente concebido para sistemas construtivos de madeira com um e dois andares.

O projeto das IP realizado com essa concepção de DFP deve compreender uma fase de estudo do processo de desmontagem, que oriente como os componentes das instalações provisórias podem ser desmontados de forma segura, adequada à preservação do meio ambiente e ajustada ao orçamento da obra.

\section{5. $\mathrm{O}$ uso do BIM}

O termo BIM ora é tratado como modelo (Building Information Model), ora como processo (Building Information Modeling). No Brasil, quando entendido como um modelo, o BIM é chamado de Modelo da Informação da Construção. Porém, quando pensado na forma de processo, é denominado de Modelagem da Informação da Construção (BIOTTO, 2012).

A modelagem de informações de construção, segundo Florio (2007), é o processo de geração e gerenciamento de informações da construção de um modo interoperável e reutilizável. Os sistemas BIM adotam modelos paramétricos dos elementos construtivos de uma edificação e permitem o desenvolvimento de alterações dinâmicas no modelo gráfico, que se refletem em todas as pranchas de 
desenho associadas, bem como nas tabelas de orçamento e especificações (COELHO; NOVAES, 2008).

No Brasil, as empresas enfrentam dificuldades inerentes à introdução de ferramentas BIM, devido à falta de profissionais capacitados e de disseminação do assunto. Scheer et al. (2011) mencionam que, para que os benefícios do BIM possam ser plenamente atingidos, existe a necessidade das etapas de desenvolvimento do projeto e do planejamento serem realizadas de forma integrada com os principais agentes envolvidos.

Segundo Dispenza (2010), o BIM pode seguir todas as etapas do processo produtivo do edifício: análise de viabilidade, projeto conceitual, detalhamento do projeto, análise e cálculo estrutural, documentação (projetos, cronogramas, orçamentos etc.), pré-fabricação, execução, apoio logístico, operação e manutenção, renovação e demolição. Assim, o BIM facilita e possibilita que as informações estejam disponíveis por todo o ciclo de vida de uso do edifício.

Além de a edificação permanente ser, naturalmente, o objeto de uso de BIM, as construções temporárias em canteiro de obra também podem contar com esse tipo de ferramenta em sua concepção. De modo geral, espera-se que as fases de montagem e de desmontagem no canteiro sejam mais bem implementadas a partir de um estudo específico com uso de programas BIM.

\section{Estudos de Caso e Simulações}

A seguir, serão apresentados os principais resultados do trabalho relacionados às etapas de fabricação, montagem e desmontagem das IP.

\subsection{Fabricação das Instalações Provisórias}

Foi visitada uma fábrica produtora de instalações provisórias para canteiro de obras, localizada na cidade de São Paulo, que se dispôs a colaborar com a pesquisa. A fábrica teve sua origem em 1988, com o intuito primeiro de comercializar madeira. Posteriormente, dedicou-se à venda de edificações pré-fabricadas em madeira, buscando soluções padronizadas, adaptáveis e viáveis financeiramente.

Durante a visita, foram feitos registros fotográficos, tal como os indicados nas Figuras 3 a 6, a seguir. Verificou-se que, como o processo de produção é padronizado, a montagem de cada componente é rápida, totalizando dois minutos para o corte da madeira, cinco minutos para a montagem da tesoura e quatro minutos para a montagem dos painéis. Após a montagem, os componentes são estocados e ficam disponíveis para expedição às obras. 


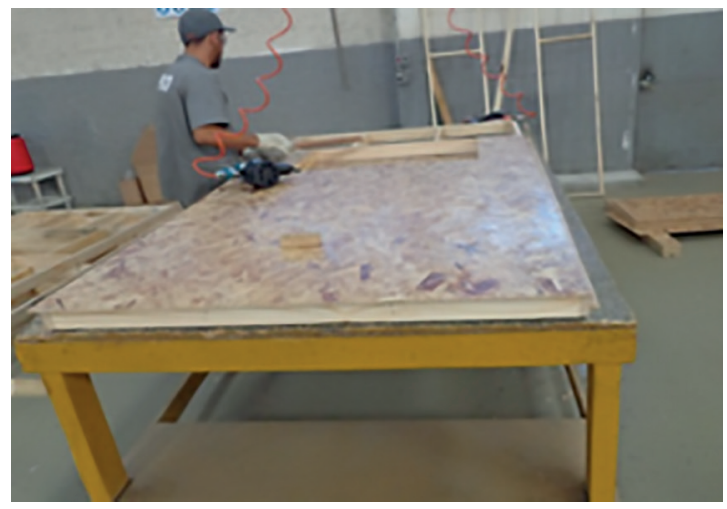

Figura 3 - Bancada para fabricação do painel. Fonte: Souza, 2016.

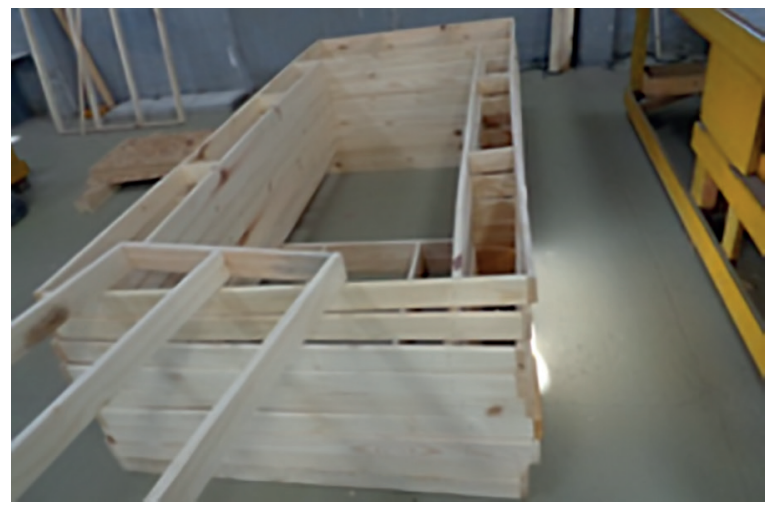

Figura 4 - Vista da estrutura dos painéis. Fonte: Souza, 2016.

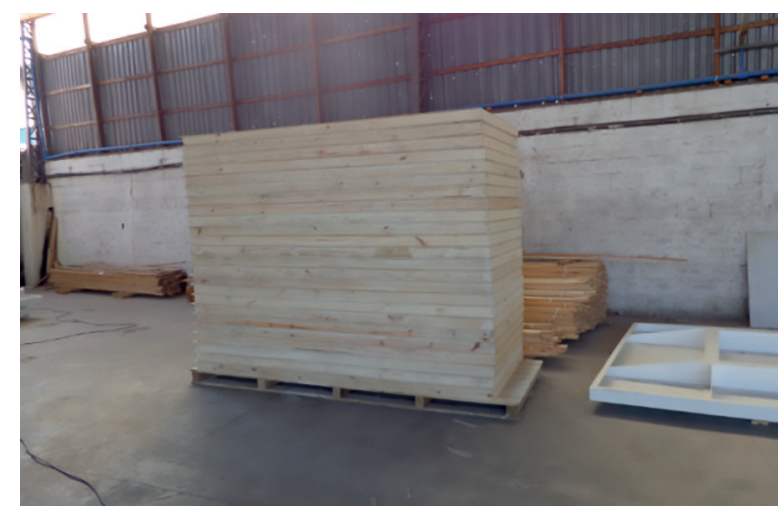

Figura 5 - Vista dos painéis estocados. Fonte: Souza, 2016. 


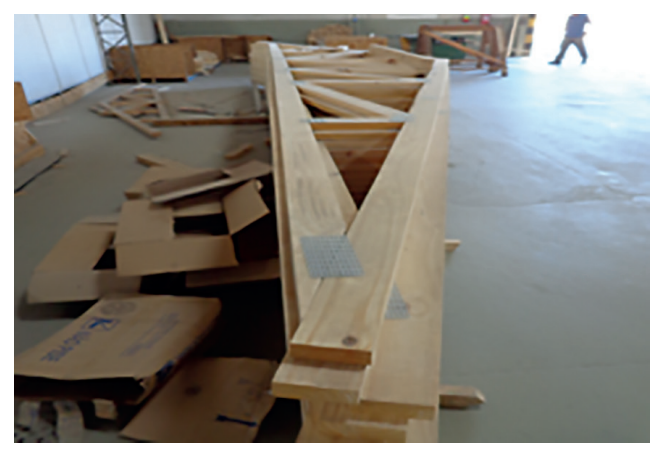

Figura 6 - Vista do estoque de tesouras da cobertura. Fonte: Souza, 2016.

A Figura 7 exemplifica o fluxograma do processo de fabricação dos componentes em madeira nessa fábrica, desde a extração da matéria prima em madeireira (compra de madeira certificada) até a estocagem e distribuição dos componentes.

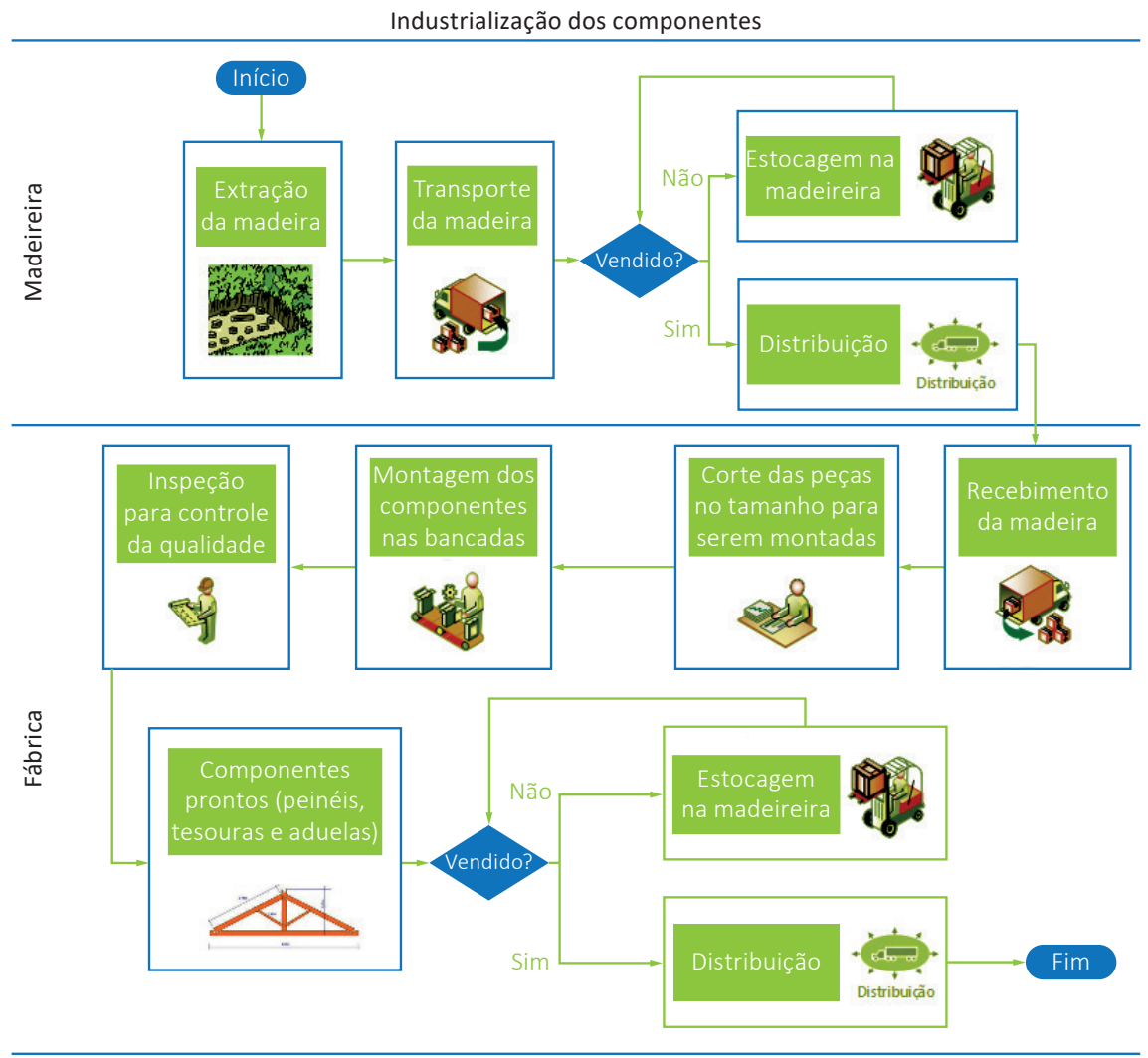

Figura 7 - Fluxograma do processo de fabricação dos componentes das instalações provisórias. Fonte: Souza, 2016. 
A partir do registro das etapas de produção, foi feita a simulação 4D da fabricação dos componentes, conforme Figura 8. Tal simulação foi obtida por meio da importação do modelo 3D e do planejamento da montagem no Navisworks. Primeiramente utilizou-se a ferramenta Autodesk Rendering para adicionar o tipo de material utilizado em cada elemento para que os componentes virtuais ficassem mais parecidos com o real. Foi necessário escolher a opção construction na ferramenta TimeLiner e associar cada componente do modelo 3D a uma atividade do planejamento, que podia ser visualizada e facilmente alterada no cronograma de Gantt. Depois, usou-se a opção simulate para exportar a animação em vídeo no formato "avi".

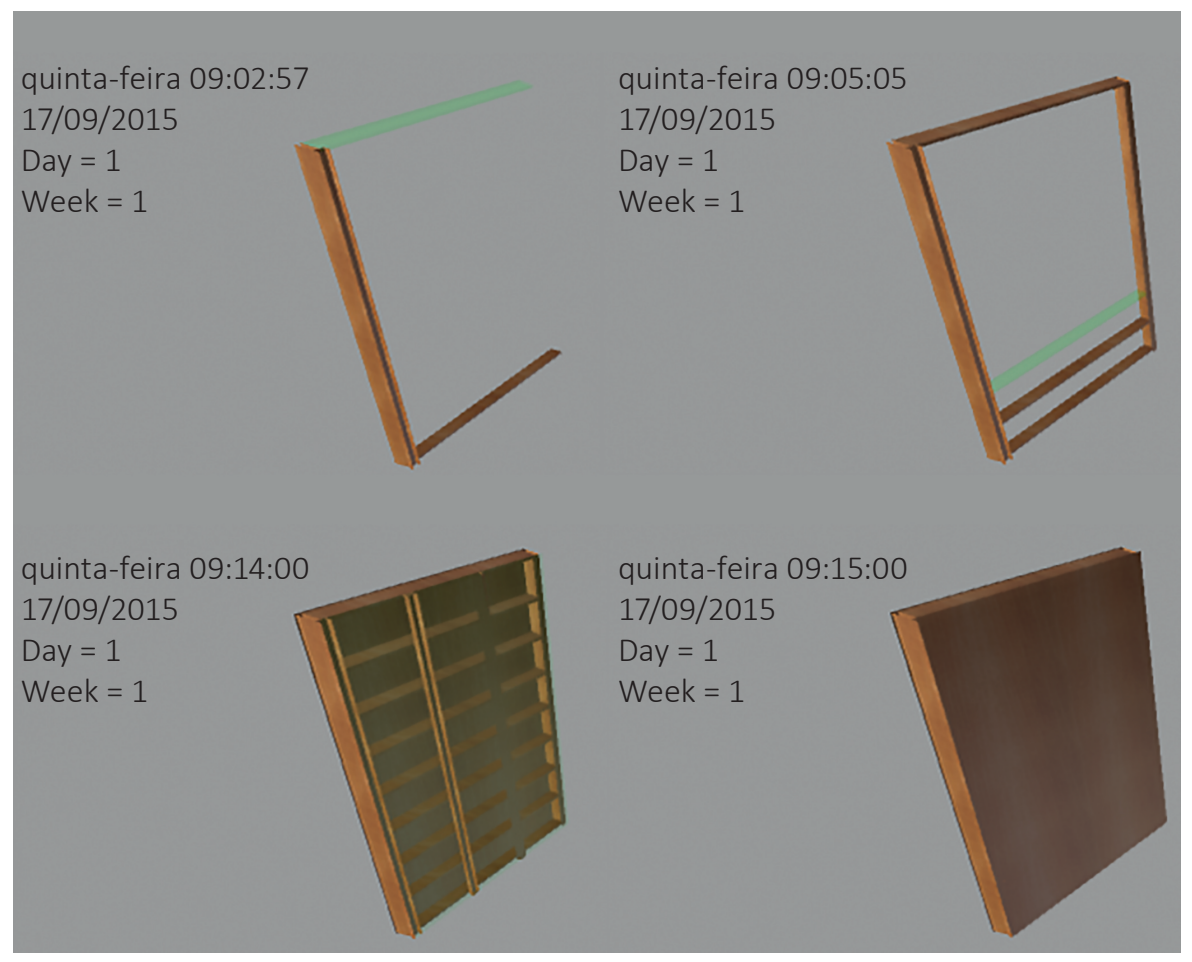

Figura 8 - Simulação 4D da fabricação do painel no Navisworks. Fonte: Souza, 2016.

O vídeo gerado pode servir para análise de melhorias e para o treinamento de operários, facilitando o processo de produção.

\subsection{Montagem das Instalações Provisórias no Canteiro de Obras}

Foi acompanhada a montagem das instalações provisórias pré-fabricadas de madeira, produzidas pela fábrica visitada. O canteiro de obras localizava-se numa área 
de cerca de $3.200 \mathrm{~m}^{2}$ na cidade de São Paulo e eram previstas quatro construções, de acordo com Figura 9. A tecnologia da edificação registrada com "perspectiva explodida" pode ser observada na Figura 10, na qual se veem os componentes padronizados previstos: painel, porta, esquadrias, tesoura do telhado, cobertura etc..

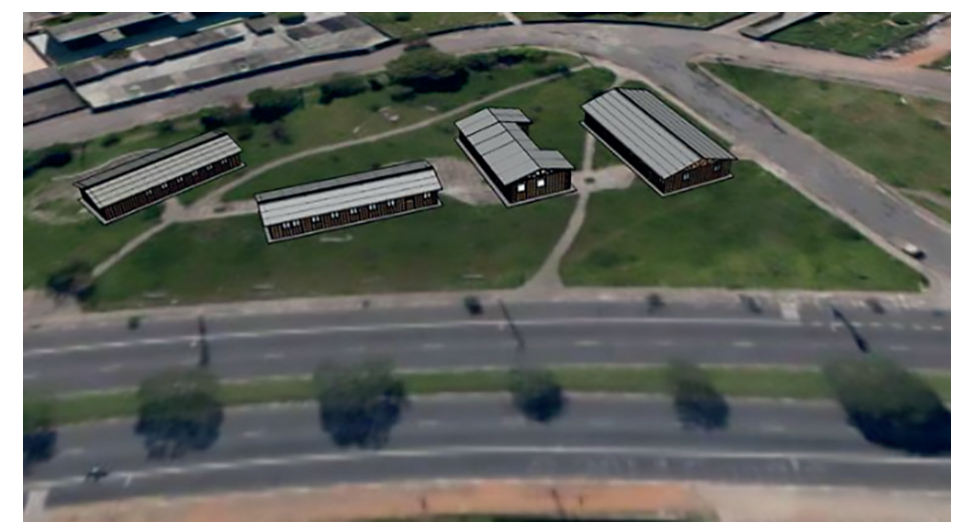

Figura 9 - Vista do canteiro de obras visitado - representação no SketchUp com mapa GoogleMaps. Fonte: Souza, 2016.

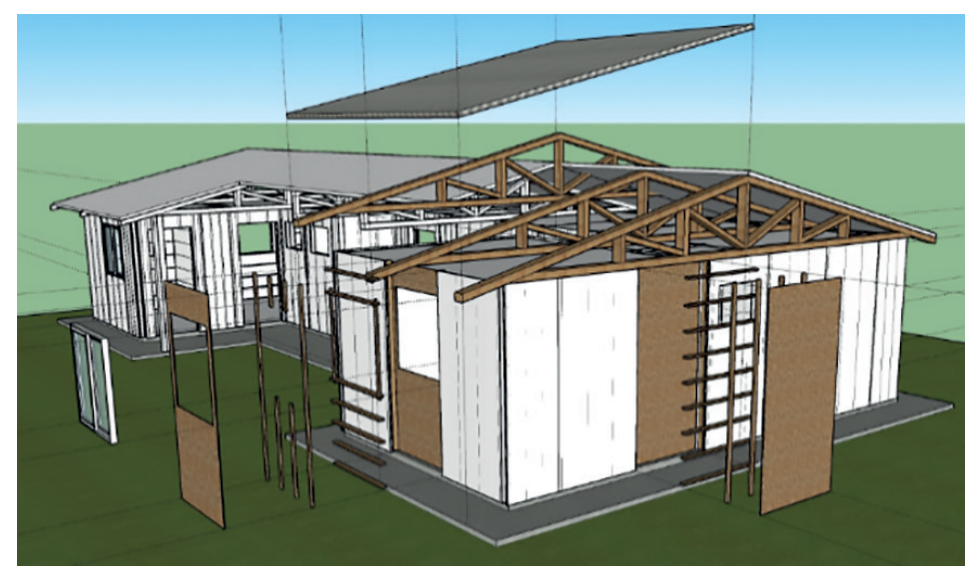

Figura 10 - Instalação provisória modelada e "explodida" no SketchUp. Fonte: Souza, 2016.

Foi escolhida uma das edificações previstas para ser modelada. Decidiu-se pelo detalhamento do projeto do escritório administrativo, conforme Figura 11, que possuía cerca de $200 \mathrm{~m}^{2}$. 


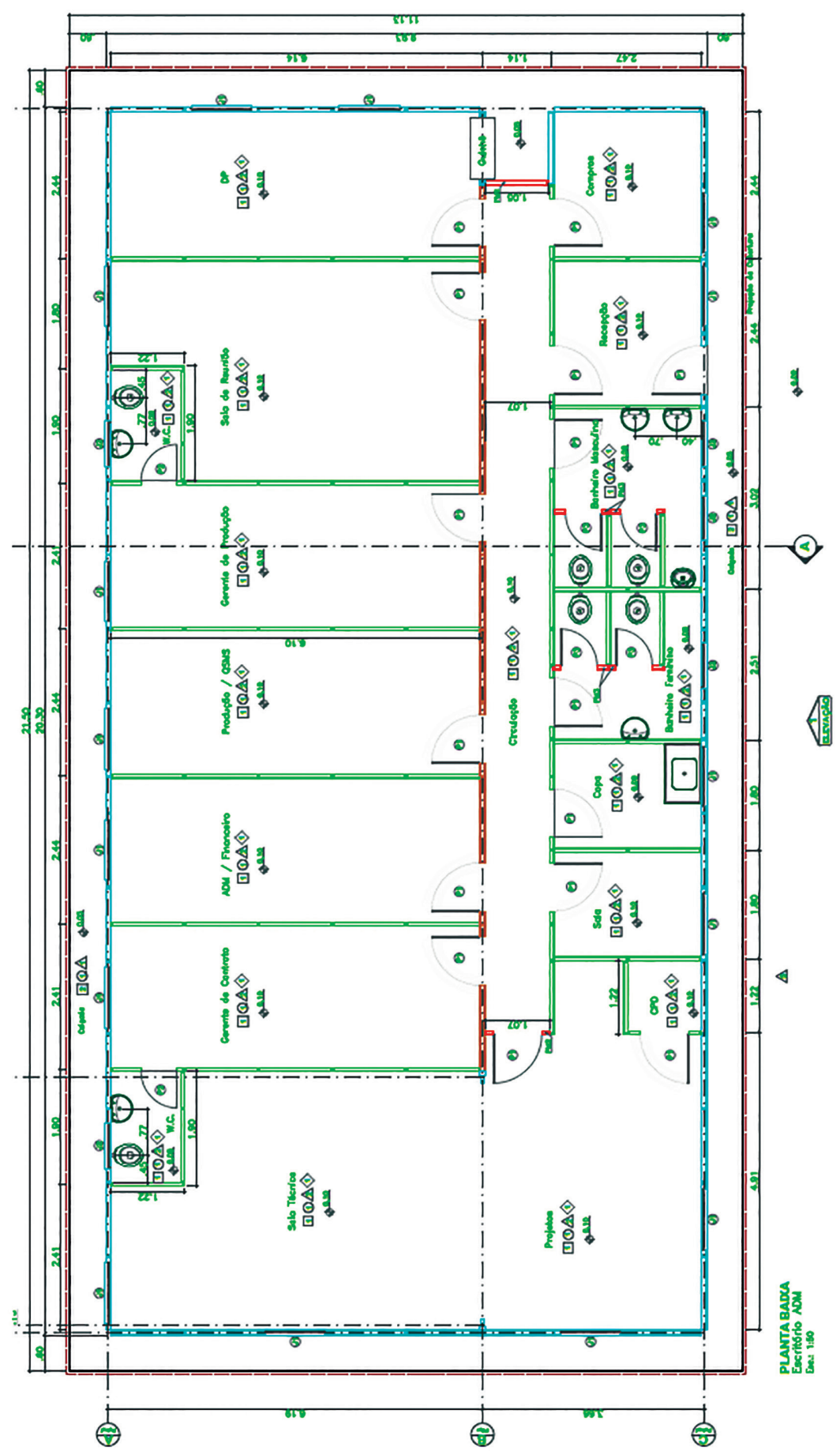

Figura 11 - Planta baixa da área administrativa. Fonte: Souza, 2016. 
As Figuras 12 a 15 mostram algumas fotos do acompanhamento da montagem das IP, sendo o primeiro passo a regularização do terreno, para que posteriormente se marcasse a fundação e se executasse o baldrame. Em seguida, inicia-se a montagem dos painéis (Figura 12). Posteriormente, instala-se uma cinta de amarração sobre os painéis e inicia-se a montagem do telhado (Figura 13). Os acabamentos finais são feitos em seguida, como a montagem de batentes para portas e janelas. Finalmente, coloca-se o forro (Figura 14) e instalam-se as peças sanitárias. A Figura 15 mostra a IP finalizada e pronta para o uso.

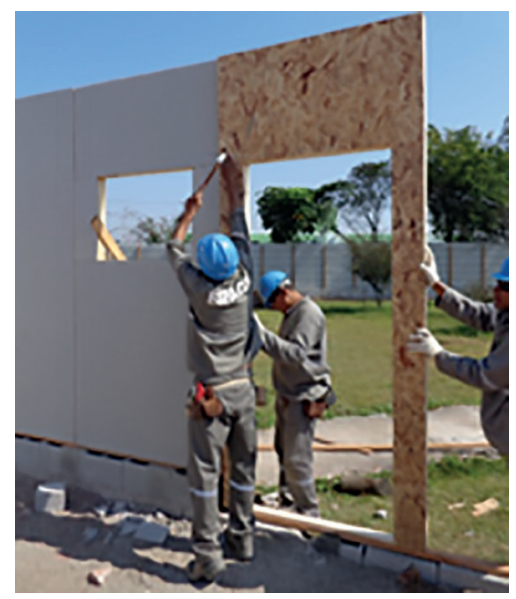

Figura 12 - Fixação dos painéis por meio de pregos com cabeça dupla. Fonte: Souza, 2016.

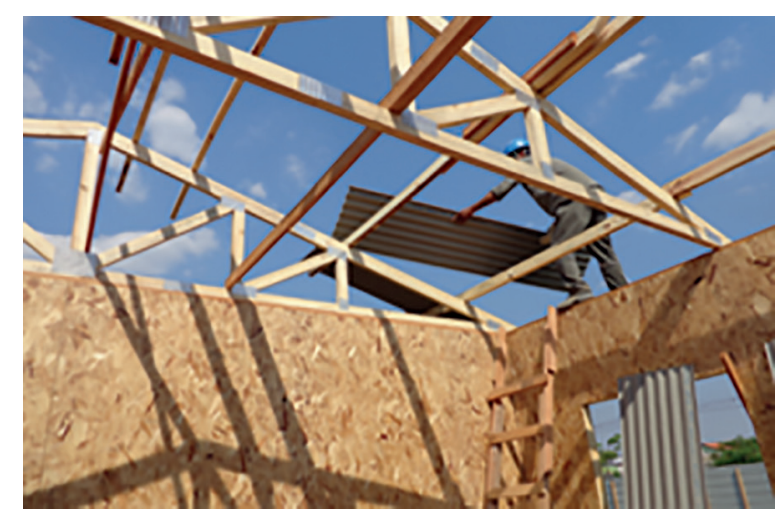

Figura 13 - Fixação das terças e telhas. Fonte: Souza, 2016. 


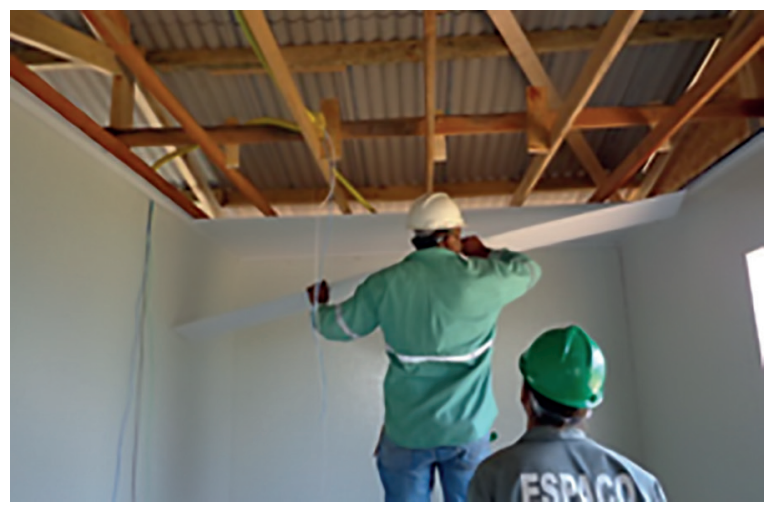

Figura 14 - Colocação do forro. Fonte: Souza, 2016.

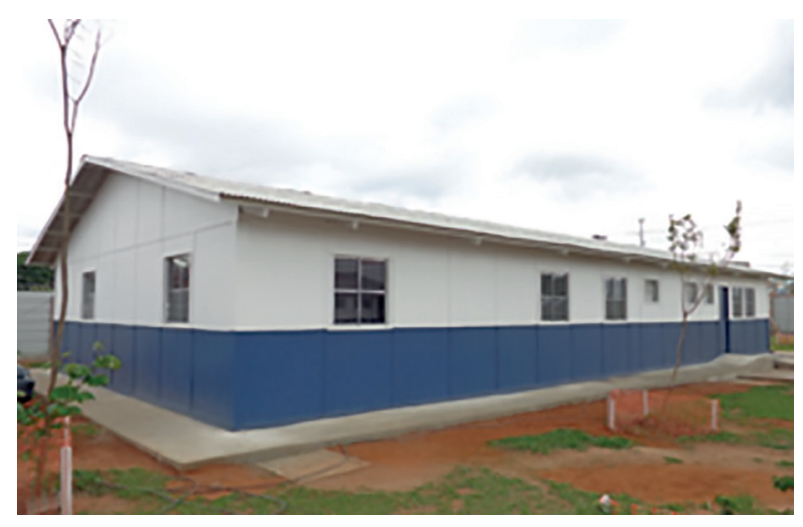

Figura 15 - Vista da obra finalizada. Fonte: Souza, 2016.

Durante o acompanhamento dos serviços, foi possível identificar alguns pontos de melhorias: (1) prover os módulos das aberturas (painéis) com as instalações prévias dos batentes - tal atividade poderia ter sido desenvolvida na fábrica em melhores condições operacionais; (2) alterar a sequência de atividades: antecipar a concretagem do contrapiso de forma a facilitar a execução dessa etapa e prover pavimentação para montagem da IP, melhorando a produtividade.

O processo de montagem dos componentes registrado durante a pesquisa está disposto na Figura 16, que sintetiza o processo realizado no canteiro até o acabamento final. 


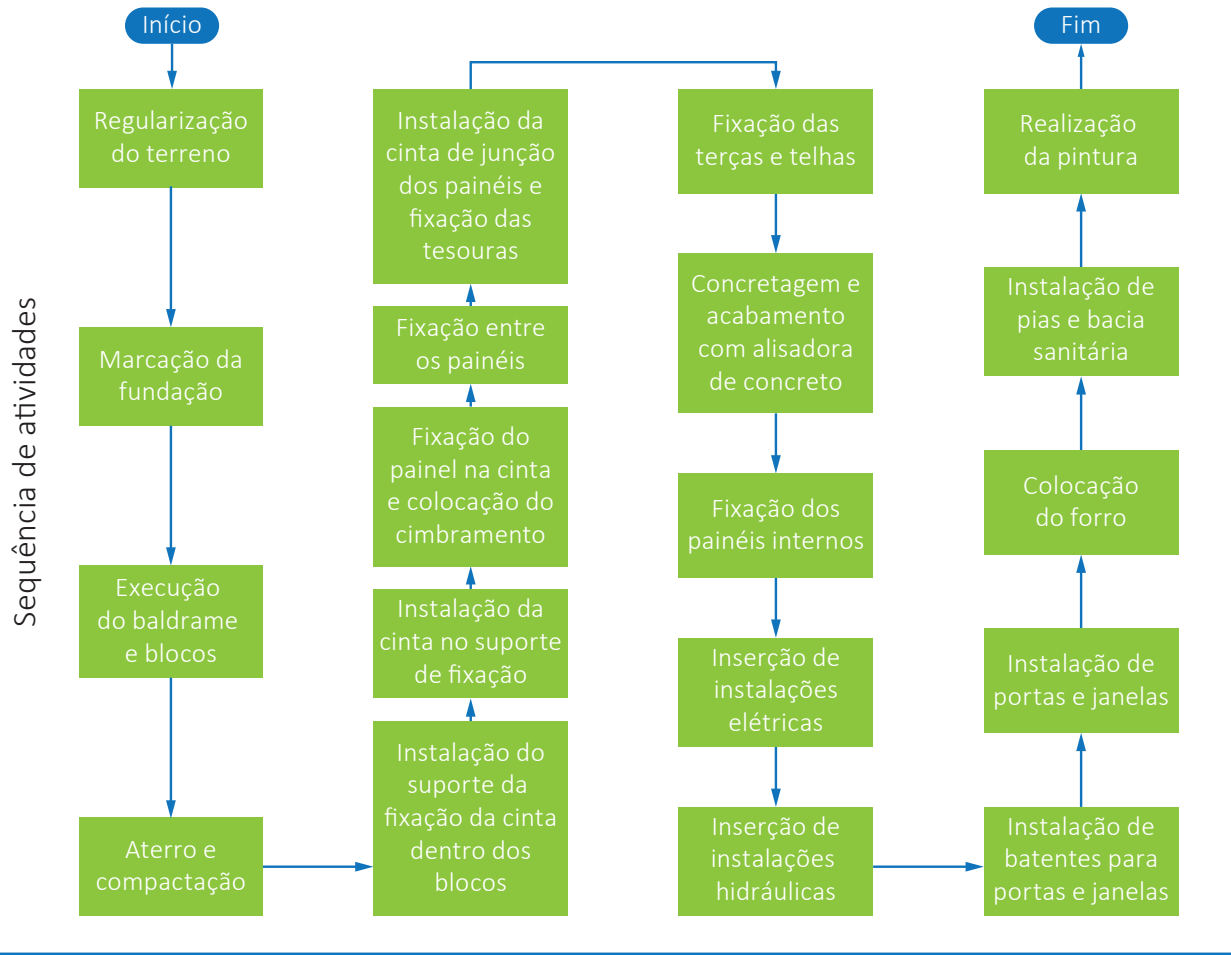

Figura 16 - Fluxograma de montagem dos componentes da IP na obra. Fonte: Souza, 2016.

Da mesma forma que o processo de fabricação, o processo de montagem das IP também foi simulado por meio da tecnologia BIM 4D, tal como na modelagem anterior. Usou-se também a ferramenta TimeLiner do Naviswork, conforme pode ser verificado na Figura 17.

A Figura 17 representa resumidamente algumas etapas do vídeo da simulação 4D no software Navisworks, na seguinte sequência: execução do baldrame, colocação de painéis, preparação para o telhado e obra concluída. 


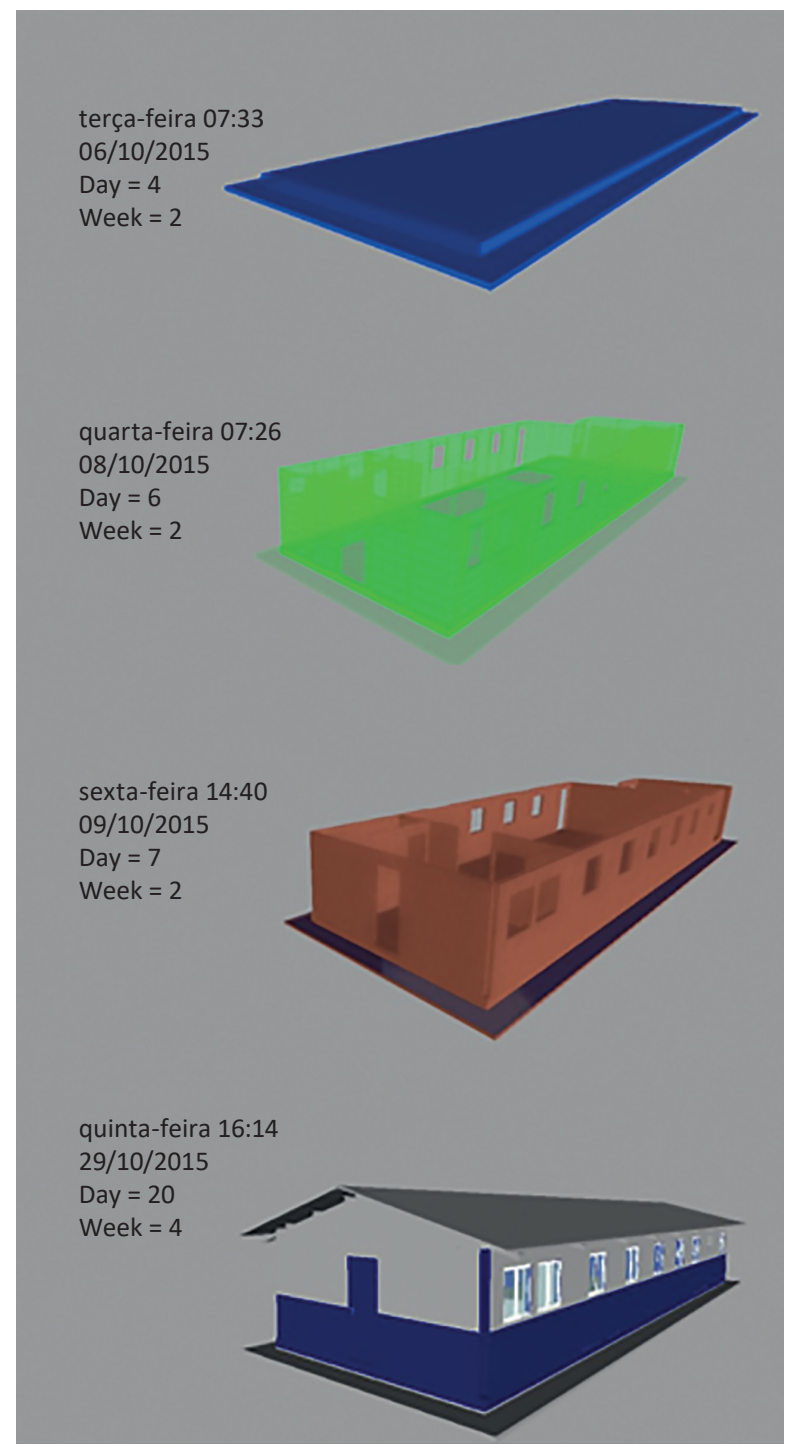

Figura 17 - Simulação 4D resumida da montagem da IP no Navisworks. Fonte: Souza, 2016.

\subsection{Desmontagem das Instalações Provisórias no Canteiro de Obras}

A simulação da desmontagem foi baseada em informações fornecidas pelo fabricante, pois não foi possível acompanhar tal etapa no canteiro de obras, durante o desenvolvimento do mestrado de Souza (2016). A desmontagem da construção foi considerada de maneira inversa à montagem observada no canteiro, tal como 
proposto por ITEC (1995). A Figura 18 ilustra o fluxograma das atividades previstas para a desmontagem, conforme relato do fabricante.

Desmontagem dos componentes na obra

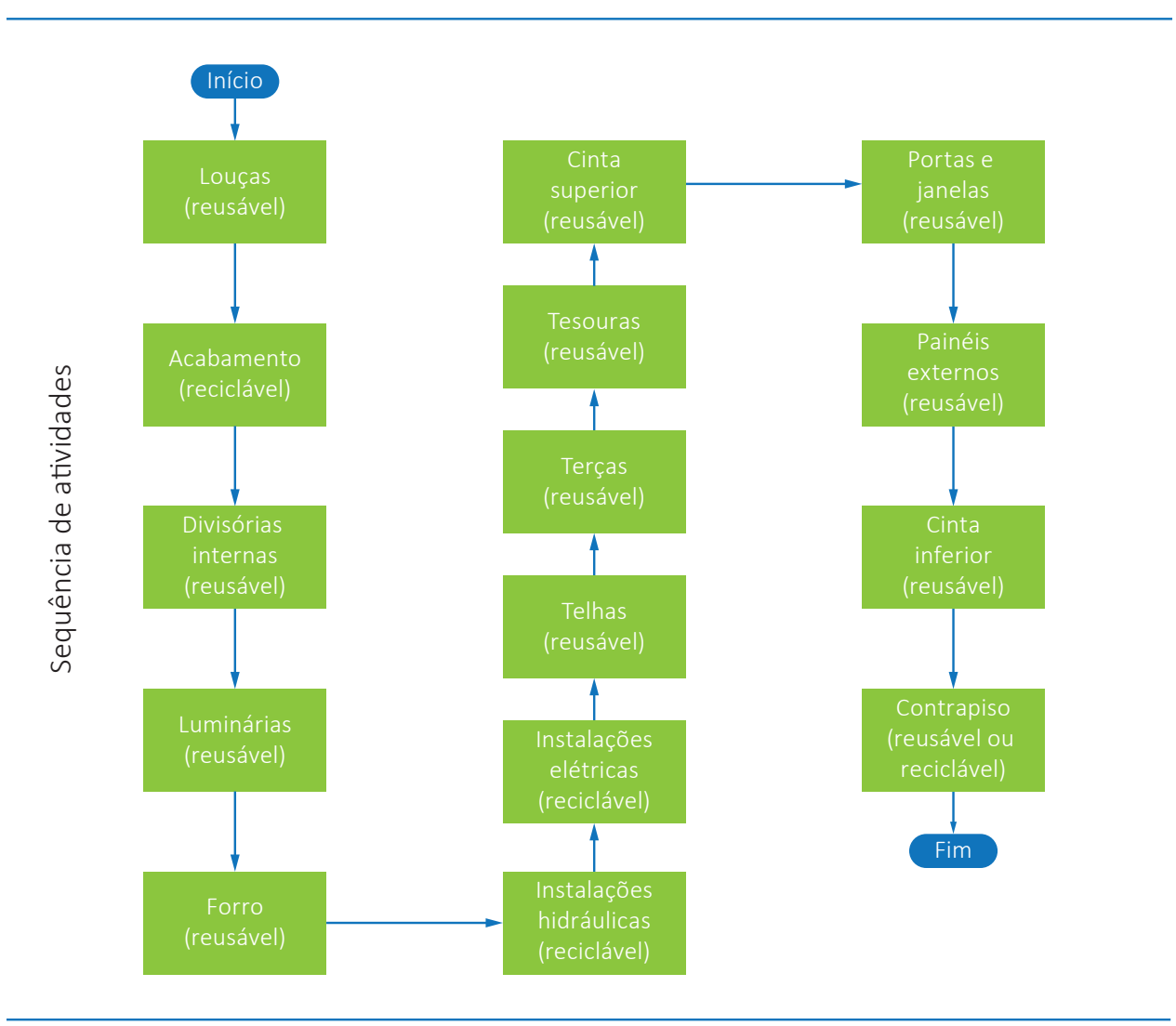

Figura 18 - Fluxograma de desmontagem dos componentes da IP na obra. Fonte: Souza, 2016.

A simulação 4D da desmontagem foi realizada com o mesmo modelo 3D da montagem, porém adaptou-se o planejamento no programa Navisworks de acordo com a sequência de desmontagem, conforme Figura 19. 


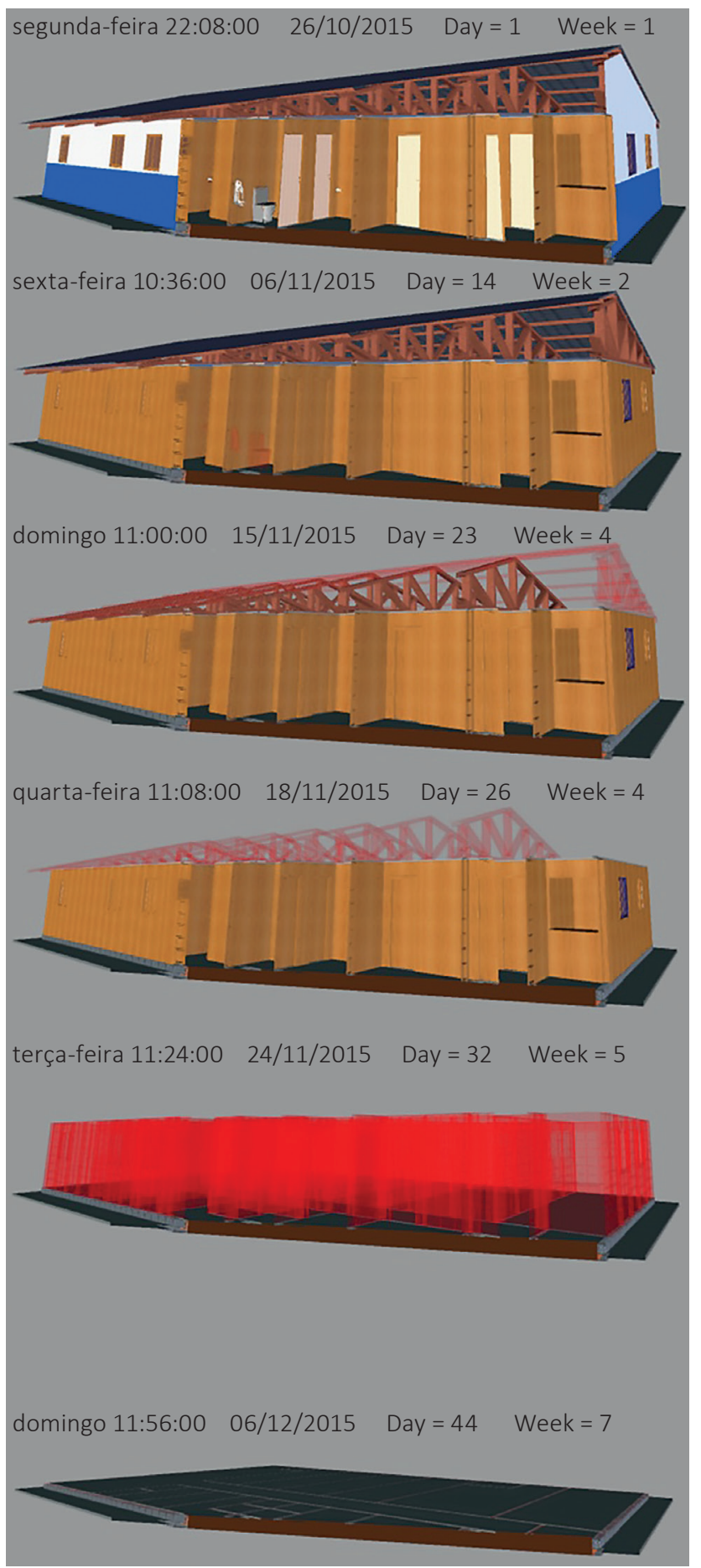

Figura 19 - Simulação 4D da desmontagem da IP no Navisworks. Fonte: Souza, 2016. 
A Figura 19 representa algumas etapas do vídeo da desmontagem dos componentes das instalações provisórias, na seguinte sequência: retirada das esquadrias e louças, retirada das telhas, das terças e das tesouras, retirada dos painéis e, por fim, é visualizado o contrapiso e a calçada, que permanecerão após a desmontagem, pois serão aproveitados para uma futura área pavimentada.

A simulação 4D da desmontagem foi modelada mais rapidamente devido à experiência anterior no Navisworks. Foi necessário alterar a opção construction para demolish na ferramenta TimeLiner. No cronograma, foi necessário alterar a duração prevista para a desmontagem. Depois, usou-se a opção simulate para exportar a animação em vídeo no formato "avi".

\section{Conclusões}

Este trabalho enfocou a importância do projeto para as IP considerando a possibilidade de desmontagem e remontagem e associando alguns benefícios ao se utilizar construções pré-fabricadas para canteiros de obras. A modelagem BIM 4D caracteriza-se como uma proposta inédita para a área de projetos, que facilita a visualização e simplificação das estruturas antes da montagem na obra.

Em relação ao acompanhamento durante a montagem, percebeu-se que as IP estudadas foram concebidas de modo a reduzir os resíduos gerados, pois foram poucos componentes cortados em obra. Destaca-se a necessidade de elaboração de um Projeto para Montagem e outro para a Desmontagem de forma compatibilizada, a fim de otimizar o uso da mão de obra, tempo e custo. No caso da desmontagem, devese prever a destinação dos materiais gerados a partir da desconstrução.

O potencial de uso do BIM para a fabricação dos componentes, do projeto do canteiro e de suas instalações pode ser percebido pelos agentes a partir desses exemplos. Além da visualização da concepção dos detalhes e do produto geral, é possível obter quantitativos de materiais e de serviços e, ainda, programar a montagem e a desmontagem. Na modelagem 4D, foi facilmente observado que alguns passos poderiam ser alterados como forma de melhorar a produtividade.

Os vídeos das simulações da construção foram gerados por meio da modelagem BIM 4D, sendo necessário contar com conhecimento dos processos de fabricação e de construção. Houve a necessidade de o pesquisador fazer várias simulações da modelagem virtual até chegar ao resultado que represente a realidade da melhor forma. Também foi necessário entender a integração entre os programas computacionais. Sabe-se que podem ser buscadas alternativas para combinação dos programas. 


\section{Referências}

AMARAL, A.T. O uso do método DFA (Design for Assembly) em projeto de produtos objetivando a melhoria ergonômica na montagem. 2007. 127f. Dissertação (Mestrado em Engenharia de Produção) - Universidade Federal de São Carlos, São Carlos.

BARKKUME, A. Deconstruction and Design for Disassembly. 2008. Disponível em <http:// www.academia.edu/178424/Deconstruction_and_Design_for_Disassembly>. Acesso em: dez. 2016.

BIOTTO, C.N. Método de gestão da produção na construção civil com uso da modelagem BIM 4D. 2012.182 f. Dissertação (Mestrado em Engenharia Civil) - Universidade Federal do Rio Grande do Sul, Porto Alegre.

BOOTHROYD, G.; ALTING, L. Design for Assembly and Disassembly. CIRP Annals Manufacturing Technology. v. 41, n. 2, 1992, pp. 625-636.

BRASIL. Ministério do Trabalho e Emprego. Norma Regulamentadora 18 (NR-18): Condições e meio ambiente de trabalho na indústria da construção. 2015. Disponível em: http://www. mte.gov.br/seguranca-e-saude-no-trabalho/normatizacao/normas-regulamentadoras/ norma-regulamentadora-n-18-condicoes-e-meio-ambiente-de-trabalho-na-industria-daconstrucao. Acesso em: dez. 2016.

COUTO, A.B.; COUTO, J.P.; TEIXEIRA, J.C. Desconstrução: uma ferramenta para a sustentabilidade da construção. In: Inovações Tecnológicas e Sustentabilidade, 2006, Anais... São Paulo. NUTAU 2006,

COELHO, S.B.; NOVAES, C.C. Modelagem de Informações para Construção (BIM) e Ambientes Colaborativos para Gestão de Projetos na Construção Civil. In: Workshop Brasileiro de Gestão do Processo de Projetos na Construção de Edifícios, 8., 2008. Anais... São Paulo, 2008.

CROWTHER, P. Design for Buildability and the Deconstruction Consequences. In: Design for Deconstruction and Material Reuse. CIB Publication, 272, 2002.

DIAS, C. M. Etapas do Ciclo de Vida de Construções Provisórias para Canteiros de Obras. 2013. 119f. Trabalho de Conclusão de Curso (Curso em Engenharia Civil) - Universidade Federal de São Carlos, São Carlos.

DISPENZA, K. The Daily Life of Building Information Modeling (BIM). 2010. Disponível em: http://buildipedia.com/aec-pros/design-news/the-daily-life-of-building-informationmodeling-bim. Acesso em: jan. 2016.

FLORIO, W. Contribuições do building information modeling no processo de projeto em arquitetura. In: Seminário TIC 2007 - Tecnologia da Informação e Comunicação na Construção Civil, 2007. Anais... Porto Alegre: TIC 2007.

GUY, B. Design for Deconstruction and Materials Reuse. 2003. Center for Construction and Environment, Gainesville, Florida; Scott Shell, Esherick, Homsey, Dodge \& Davis Architecture, San Francisco, CA. Disponível em: http://citeseerx.ist.psu.edu/viewdoc/ download?doi=10.1.1.624.9494\&rep=rep1\&type=pdf. Acesso em: dez. 2016. 
GUY, B.; OHLSEN, M. Creating business opportunities through the use of a deconstruction feasibility tool. Paper 3. 12p. 2003. In: CIB Publication 287. Proceedings of the 11th Rinker International Conference May 7-10, 2003 Gainesville, Florida, USA. Disponível em: http:// www.cce.ufl.edu/wp-content/uploads/2012/08/Deconstruction_and_Materials_Reuse. pdf. Acesso em: dez. 2016.

ITEC. Institut de la Tecnologia de la Construcción de Catalunya. Manual de Desconstrucción. 1995. Disponível em: <http://www20.gencat.cat/docs/arc/Home/LAgencia/Publicacions/ Residus\%20de\%20la\%20construccio/desconstr.pdf> Acesso em: dez. 2016.

KIBERT, C.J.; CHINI, A. R. Overview of Deconstruction in Selected Countries. CIB Publication 252, 2000.

KUO, T-C.; HUANG, S.H.; ZHANG, H-C. Design for manufacture and design for ' $X$ ': concepts, applications, and perspectives. Computers and Industrial Engineering. n. 41, 2001. p. 241260.

LIPSMEIER, K.; GÜNTHER, M. Manual Europeu de Resíduos da Construção de Edifícios. Minho: Institute for Waste Management and Contaminated Sites Treatment of Dresden University of Technology, v. 1, 2002.

LOPES, M. F. Implementação da desconstrução na indústria da construção nacional. $183 f$. 2013. Dissertação (Mestrado Integrado em Engenharia Civil) - Universidade do Minho, Portugal.

MANFREDINI, C; SATTLER, M.A. Estimativa da Energia Incorporada a Materiais de Cerâmica Vermelha no Rio Grande do Sul. Ambiente Construído, v. 5, n. 1, p.23-37, 2005.

REVEL, M. La prefabricacion em la construcion, 1.ed. 1973. Bilbao: Urmo. 457p.

SACKS, R.; PARTOUCHE, R. Empire State Building Project: Archetype of "Mass Construction". Journal of Construction Engineering and Management. v. 136, n. 6, p. 702-710, 2010.

SAURIN, T.A.; FORMOSO, C.T. Planejamento de canteiros de obra e gestão de processos. Recomendações Técnicas HABITARE. v. 3, 112p., 2006.

SCHEER, S.; CARVALHO, W.; SANTOS, A. Análise da situação atual e proposta para a produção e gestão de projetos civis em instituições públicas de ensino. In: Simpósio Brasileiro de Gestão e Economia da Construção (VII SIBRAGEC), 2011. Anais... Campinas, 2011.

SOUZA, F.B. Processo produtivo das instalações provisórias de madeira para canteiros de obras. 2016. 103f. Exemplar aprovado em qualificação de mestrado (Programa de Pósgraduação em Estruturas e Construção Civil) - Universidade Federal de São Carlos, São Carlos.

VIVAN, A.L.; PALIARI, J.C. Design for Assembly aplicado ao projeto de habitações em Light Steel Frame. Ambiente Construído, v. 12, n. 4, p. 101-115, 2012. 